\title{
Case study of industrial green development on the perspective of ecological civilization in China
}

\author{
Dan $\mathrm{Liu}^{1, *}$ and $\mathrm{Li} \mathrm{Liu}^{2}$ \\ ${ }^{1}$ Vice Professor, A nshan Normal University, A nshan, China \\ ${ }^{2}$ V ice Professor, U niversity of Science and Technology Liaoning, A nshan, China
}

\begin{abstract}
With the increasing concern of ecological crisis and sustainable development, the issue of green development has aroused widespread focus in the academic and practical domain. Green development and ecological civilization are especially important to developing country, which interact and both are the basis of sustainable development. This paper analyzed the present background, status, importance and problem about green development in China and shared a case study of the practice in Green Development in A nshan, as well as proposed specific tactics to promote realization of goal of green development and ecological civilization on the two main direction from the perspective of ecological civilization, which enriches the theory of green development and ecological civilization and guides the practical implication and implement of industry transformation.
\end{abstract}

\section{Introduction}

Green development and ecological civilization have been concentrate since it is proposed in the report of 18th National Congress in 2012, which is the premise to realize B eautiful China strategy. The core of green development is coordinate and balancing the relationship between economic development and the ecological environment, that is, harmonious sustainable development. The path to realize industrial green development is divided into two directions, one of which is carrying out green transformation and upgrading of existent industries from the aspects of technology, mode and management; the other is to optimize and upgrade the industrial structure, continuously eliminating backward production capacity, and adjusting the proportion between traditional industries and green emerging industries. Specific tactics is discussed in the sequent session based on the status analysis.

\section{Background}

Globalization increased the concerns about environmental impacts on social economy development. Meanwhile, more and more country realized the sustainable development depend on well environmental and ecological balance, and begin to invest in environmental management. As a rapid developing country, China has good awareness that the country needs to catch up with the global trend in environment management in order to develop a sustainable economy. So, China has promulgated a series of policies and regulations, "Environmental Protection Law of the People@ Republic of China", "A ir Pollution Prevention and Control Action Plan", "Water Pollution Prevention Action Plan", "Overall Plan for Ecological Civilization System R eform"

According to the "Environmental Economic Policy Annual Report 2017f issued by the Environmental Planning Institute, the cost of ecoenvironmental degradation in China continued to increase in the period of 2008-2015, and the growth rate was roughly equivalent to the economic growth rate in the same period. The cost of ecological environment degradation in China has a great imbalance of spatial distribution, the ecological damage in the western region is obviously, and the cost of environmental degradation in the eastern region is relatively high. This shows that behind the continuous economic growth, China $\$$ environmental problems are deteriorating and the cost of governance is increasing.

In 2017, China@ investment in environmental pollution control was 9.5538 trillion, an increase of 31.915 billion than 2016, accounting for $1.16 \%$ of GDP. The national energy conservation and environmental protection expenditure budget increased $0.5 \%$ compared with 2016 . The largest proportion of investment in industrial pollution control is the completion of investment in the treatment of waste gas projects, accounting for $65.74 \%$ of the total, which is an upward trend year by year. In 2017, the central government allocated a total

Corresponding author: eadyliu2017 @ gmail.com 
of 49.7 billion in environmental protection funds. This fund is mainly used for activities such as water, atmosphere and soil pollution prevention and control. In the United Nation climate meeting, China's aggressive goal of achieving $60-65 \%$ carbon emissions reduction in 2030, comparing to that in 2005 is respectful (China News, 2015). In its $N$ ational Thirteen Five- $Y$ ear Strategy, China set the goal of $15 \%$ energy saving in 2020 , comparing to that in 2015 (National Development and Reform Commission, 2016). Such determination has become China's national policy.

\section{Literature review}

Increasing globalization causes concerns about environmental impacts on economy and sustainable development (WTO,2000). Some critics assert that globalization promote the development of polluting industries in countries with low environmental regulations and accelerated environmental degradation. However, an experiment study based on the survey in China found that globalization increase self-regulation pressures on firms in low-regulation countries and have positive impact on environmental performance. (Christmann \& Taylor, 2001). Organization is an open network system (Borgatti \& amp; F oster, 2003), in which the members develop themselves through resources sharing and exchanging. As a part of network, environment cat as an very important role, which is the premise to sustainable development and happy life. Environmental issues cannot be ignored. The strategic mission of ecological civilization construction and green development is an important guide to solving environmental problems.

\subsection{Concept of green development and ecological civilization}

The research of environmental and ecological issue original Carson (1962). The concept of industrial ecology is proposed by Erkman (1997), which combine the two concepts of pollution control and cleaner production form a new practice. The U nited Nations Environment Program (2007) defines green economy as an economy that concern the balance between human and nature and supply more decent jobs with high salary. The discussion of the green economy is no longer limited to improving the single dimension of the ecological environment, rather than emphasizes the overall transformation of the economic system, thereby achieving an ecological environment and economic balance and coordinated development. The United Nations Development Program (2010) renew the definition of green economy, which bring about human well-being and social equity and significantly reduce environmental risks and improve the lack of ecologically resource. The definition extends the goal of green economy development to the whole social system and focus on coordination and balance of mutual economic development, environmental protection, and social equity. Curbing the damage to the ecological environment is necessary premise to realize green development (Granger, 1999). Hu and Zhou (2014) summarize the connotation, characteristics, functional orientation, mechanism and strategic of green development and proposed the Three-Circle M odel of green development and the framework of mechanism analysis. Ecological civilization is defined as a higher civilization which represent the progress of human civilization and profound reflection on traditional form of civilization, particularly industry civilization (Zhang, Li \& An, 2008). Eco- efficiency evaluation has been broadly applied in different industry and organization (Zhang, J, Chang \& Zhang, L, 2017).

\subsection{Importance of green development}

Green development can bring benefits in three aspects, ecological and environmental benefits, economic benefits and social benefits. First, it has improved the utilization efficiency of natural resources, promoted the transformation of production and lifestyle to low-carbon and the diversified development of energy, and realized sustainable development of energy. Second, it promotes the transformation of production means and sustainable economic development by guiding industrial upgrading and structural optimization. Furthermore, it focuses on innovation, which is conducive to the promotion and application of new technologies and new models and improves production and resource efficiency. In summary, green development promoted ecological and social civilization.

\subsection{Status of green development in China}

The environment problems are seriously in air pollution, water pollution, land desertification and ecological diversity, among which air pollution and water pollution problems are particularly prominent. Data shows that about seventy-five percent of the city (ङ) air quality above the prefecture level exceeded the standard, and most of the surface water in China suffered from different degrees of pollution (Iyiouzhiku, 2016). The main sources of pollution were industrial emissions ( $M$ inistry of Environmental Protection, 2016). However, it is favorite that more and more people focus on the environmental and ecological issue. According to the China Sustainable Consumption Research Report, there are more than seventy percent of consumers have some green consumption awareness, who believe that personal consumption behavior is directly related to the 
environment (China Chain Store \& Franchise Association , 2017).

\section{Case study : the practice of green development in Anshan}

In 2015, A nshan City was officially approved by the $M$ inistry of Industry and Information Technology as the first pilot city for industrial green transformation and development in the country, and became the only selected city in the Northeast. The development of green transformation is the only way for industrial development under the condition of scarce resources. Especially for the old industrial base cities such as Anshan, it has become the first pilot city for industrial green transformation and development in China.

\subsection{The material base and status}

As a industrial city with iron and steel products mining and processing as its pillar industries, A nshan has rich mineral resources. These industries are concentrated on high energy consumption such as steel, cement, electrolytic aluminium, caustic soda, calcium carbide, ferroalloy, yellow phosphorus and zinc smelting. enterprise. These industries have caused severe air pollution and excessive sulphur dioxide emissions. Anshan ( economic development relies excessively on heavy-duty industries with high energy consumption and high pollution, which makes A nshan ( economic development structure too single to sustain development. It also caused the tight supply and demand of A nshan energy. In addition to mineral resources, Anshan also has a wealth of historical and cultural tourism resources, such as hot spring resources and Qianshan Taoist cultural resources. Meanwhile, Anshan also has abundant agricultural resources. Nanguo Pear is a well-known agricultural product of Anshan, which has a good reputation in China.

\subsection{The implement of green development points of style}

4.1.1.Accelerate the adjustment of green production methods in traditional industries.

As an pillar industry of A nshan, Ansteel Group has vigorously developed and utilized green new energy in recent years. It has taken the lead in implementing domestic wind power generation, solar energy utilization and desalination technology, and has become a Tridemonstration project f for metallurgical enterprises to use clean energy. In the new factory of A nsteel Group - Bayuquan new plant, electric furnace steelmaking replaced coal burning, industrial water consumption from seawater desalination, solar energy, wind energy to maintain factory lighting and heating and other environmental protection technologies promoted the green transformation of A nsteel Group and ecological civilization construction in A nshan.

\subsubsection{Constructing a green industry layout based on the characteristics of Anshan} resources.

For the traditional steel processing industry, it is necessary to strengthen the technological innovation of enterprises and help enterprises realize the transformation from black industry to green industry through technological innovation. In addition, it is necessary to fully exploit the existing natural resources advantages of Anshan to develop diversified green agriculture, tourism, and characteristic cultural health industries. Firstly, government vigorously develop green ecological agriculture based on Nanguo Pear. Focus on the development of ecological and rural urban agriculture to adjust the agricultural structure and develop green ecological agriculture. Based on the A nshan specialty $\mathrm{N}$ anguo Pear, government vigorously develops urban green ecological agriculture integrating leisure experience, tourism and holiday and ecological sightseeing by highlighting the experience of agricultural leisure sightseeing and farming culture. Secondly, the transformation of traditional agriculture to urban green ecological agriculture is promo red to actively develop organic green and pollution-free food industry, promote the deep processing of agricultural and sideline products, and increase agricultural efficiency.

\subsubsection{Accelerate the upgrading of traditional industries with high technology.}

With the continuous implementation of the environmental protection renovation projects of steel enterprises such as Ansteel Group, Houying Group and Baode Group, Anshan has continuously promoted the green transformation of traditional industries. Ansteel West Steelmaking Plant adopts the production process of hot metal pretreatment, converter steelmaking, etc., and promotes the greening of production technology in the smelting process. Make full use of low-quality magnesite to develop new products, optimize production processes, and increase the additional value of magnesite products. The traditional magnesite industry is developing towards green. Improve the comprehensive recycling level of resources to build a circular economy industrial chain. A beautiful and livable ecological environment has been created 
through the implementation of greening, landbuilding, gardening and city-building projects. In addition, the government promote the prevention and control of water pollution in the Liaohe River Basin, and by 2017 , the urban sewage collection rate has reached $100 \%$.

\subsubsection{Promote the development of cultural tourism industry.}

A nshan is rich in tourism resources, with a profound religious and cultural history of the Qianshan Scenic A rea and the fascinating Jade Buddha, plus the characteristic hot spring resources and jade resources, as well as the local book-style book culture and $Y$ angge culture, which are good foundation for the development of cultural tourism industry. The government fully integrated the religious history and culture, natural landscape, jade culture and various intangible cultures of Anshan, perfected the construction of related tourism service facilities, and improved the transportation, information, and business of the Anshan downtown tourist area. The comprehensive tourism service functions such as shopping, accommodation and catering have successfully created the $5 \mathrm{~A}$ tourism area - Qianshan Tourism Scenic A rea. Relying on Anshan $($ e existing scenic resources Qianshan Tourism Scenic Resort, Y ufoyuan and Tanggangzi Hot Spring Resort, the development of Anshan hot spring tourism industry chain have been constucted. The strategic mission is the cluster development of leisure tourism industry with the goal of creating a thot spring leisure complex $\int$, which is a diversified cluster development model with functional aggregation.

\subsubsection{Developing leisure and health industry based on characteristic hot springs.}

The government combines the development of hot spring resources with the tourism culture of Qianshan, and takes the approach of clustering and diversified development, and established the characteristic brand image of tourism resources of A nshan Hot Spring. The religious culture of Qianshan, the jade culture of $X$ iuyan and the hot spring health culture were fully integrated to create a healthy industrial chain of religion, jade and hot spring health, which is diverse cluster development model. Using the profound influence of jade culture in Chinese traditional culture, the jade culture and hot spring culture will be perfectly combined to enhance the city brand and popularity of Anshan. In addition, the hot spring tourist area extended various functions such as recuperation, leisure, vacation, entertainment, conference and sightseeing, and have formed a diversified comprehensive industrial belt focusing on health, conference, real estate, sports and leisure and agriculture.

\subsection{Ecological civilization construction achievements}

As one of the pilot areas for the regional industrial green transformation and development in China, Anshan concerned greatly on industrial green development. With the accelerating pace of transforming the economic development mode, Anshan $($ industry has gradually got rid of the structural model of Thsteel aloneness $\int$ in recent years. The proportion of the steel industry in the industrial economy above designated size has fallen from initial $80 \%$ in 1950 s to $30 \%$, which formed a more complete new green industry system including steel and deep processing, magnetite materials, equipment manufacturing, deep processing of agricultural products, textile and garment and other traditional industries and fine chemicals, high-end valves, new energy batteries, photovoltaics, energy conservation and environmental protection and other emerging industries.

In March 2015, "TH Anshan Industrial Green Transformation Development Implementation Plan (2015-2017) J passed the provincial and national assessment, which greatly accelerated the construction of Anshan $\$$ modern green industrial system and realized industrial green low carbon development in the old industrial region in $\mathrm{N}$ ortheast China. Following the "plan", Anshan vigorously developed strategic emerging industries and productive service industries, and promoted the green transformation of traditional industries. The implementation of the program focuses on the enterprise energy efficiency improvement plan, the clean production plan, the small business energy conservation action plan, and the optimization of the industrial energy structure.

\section{Discussion}

The following tactics is favourable to realize the green development and ecological civilization.

\subsection{Building green industry layout based on regional resource advantages}

The leading direction of industrial economic development is to develop new ecological industries and circle economy, accelerate industrial transformation and upgrading of heavy polluted industry based on regional resource advantage. Implementing clean production audit to gradually phase out extensive industrial economic projects with high consumption and low efficiency to realize pollution reduction and to increase resource efficiency continuously. Developing new ecological 
industry and building green brand is also helpful to industry green development.

\subsection{Improving legal and regulatory policy system about green development}

It is necessary to establish comprehensive laws, regulations and policies system to direct, motivate, support and regulate enterprise's green development following the steps. First, using financial, tax and price leverage mechanism promote the price reform of resource products to achieve the goal of energy conservation and emission reduction, such as introduction of environmental taxes, tax reduction and exemption for energy conservation and emission reduction and more invest in basic scientific research about green technology. Second, formulating specific industrial technical standards and the standard system of energy conservation and emission reduction, green production and recycling of resources promote enterprises' responsibility and obligation of preventing pollution and protecting the environment green operation. Third, improving market incentives mechanism guide and support enterprises to independently develop green technology and green industry transformation and upgrading.

\subsection{Promoting enterprises to innovate in green technology}

Green technology innovation should be based on integrating ecological and social benefits into the technological innovation target system. To strengthen cooperation between industry, enterprise should joint universities and research institutes to innovate green technology via complementing each other ( advantages and mobilize the enthusiasm and creativity of enterprises. Furthermore, guiding and supporting the transformation of the achievements of industry, university and research in green technique application via broadening diverse investment channels is also a valid mean. It is necessary to strengthen the research green technologies about new products, new processes and new energy sources that can replace traditional technologies. Enterprise should carry out green technology transformation of traditional industries, and promote the green development of the industry by speeding up the innovation of traditional technologies. It is important to cultivate a group of high-tech and green products with independent intellectual property rights, and to form a high-tech group of green industries as soon as possible. Additionally, promoting the introduction, absorption and re-innovation of abroad advanced green technologies and equipment to achieve complementary advantages is also crucial. Ultimately, improving independent innovation capabilities to protect the ecological environment and save resources rely on forming own core technologies to promote the goal of green development.

\subsection{Establishing green consumption value}

Establishment green development and ecological civilization not only require technological innovation, but also advocate the establishment of a green consumption value in the whole society, which is the important factor to achieve green development. First, publicity and education on the environmental protection should be done to improve the environmental awareness of citizen and advocate green consumption, through multiple mass media. Second, it is necessary to strengthen education about the knowledge of green products to improve the capacity of discrimination and awareness of consumers on green products. In addition, citizens should be called upon to actively participate in ecoenvironmental protection and resource conservation activities, so that citizens can consciously participate in green consumption activities and actively achieve green consumption. In summary, raising citizens ( awareness of green consumption and vigorously promoting resource conservation and rational use of resources reasonable moderation is necessary in order to create green consumption climate and achieve sustainable consumption.

\subsection{Building sharing economy platform}

The sharing economy can realize the rapid circulation and efficient allocation of idle resource elements, through building information technology platform, thereby reducing the waste of resources and improving the green efficiency of resource utilization. With the penetration of the sharing model in the industrial economy, the sharing economy has gradually expanded from shared resources such as shared travel, shared space, and shared idles to intangible resources, such as sharing skills and sharing time. In the context of technological advancement, policy support, and consumption upgrading, the sharing economy will continue to evolve and penetrate into various industries to optimize resource allocation in the whole industrial chain (e.g., production, distribution, and sales, etc.) to improve resource utilization efficiency and drive green ecologicalization of the entire industry chain.

\subsection{Popularizing and educating green development value and technology}

To establish the green development value in the whole society, it is necessary to vigorously popularize the green production knowledge to enterprises and to integrate the concept of green production into the enterprise development strategy, which improve the awareness of green production of 
all employees, and enable enterprises to proactively carry out green production. In addition, advertising the mission of Green Development through diverse media is a good way.

\section{Conclusion}

Under the context of sustainable development, green development has become a trend in the global economic and ecological environment field. The green development strategy can balance the relationship between economic growth and ecological environmental protection and it is the only and necessary path to realize the goal of comprehensive and sustainable development of society and economy. In summary, under the guidance of government, it is the key premise that formulating a comprehensive and specifically operational green development tactics consist of green development value, green instrumental system, green industry system and green consumer market. Furthermore, it is also necessary to create green development atmosphere covering the whole society. Promoting green development is the most effective path to realize ecological civilization and sustainable development.

The Project is sponsored by Liaoning BaiQianW an Talents Program.

\section{References}

1. Borgatti, S. P., \& Foster, P. C. 2003. The network paradigm in organizational research: $A$ reviewand typology. Journal

M anagement, 29(6): 991-1013.

2. Carson R.L. 1962. Silent Spring. Houghton $M$ ifflin Harcourt

3. China Chain Store \& Franchise Association. 2017.
4. China News (2015) China's 2030 low carbon commitment, accessed 20190111 from http://www.chinanews.com/cj/2015/0701/7375884.shtml

5. China Sustainable Consumption Research Report.

6. Christmann, P., \& Taylor, G. 2001. Globalization and the environment: Determinants of firm selfregulation in China. Journal of international business studies, 32(3), 439-458.

7. Erkman, S. 1997. Industrial ecology: an historical view. Journal of cleaner production, 5(1-2), 1-10.

8. Granger, C. W. 1999. Empirical modelling in economics: Specification and evaluation. Cambridge U niversity Press

9. https://www.iyiou.com/intelligence/report/

10. Hu, An-gang, Zhou, Shao-jie. 2014. Green Development: Functional Definition , $M$ echanism A nalysis and Development Strategy. Population, Resources and Environment ,3,14-20.

11. J oint Task Force of the Environmental Planning Institute of the Ministry of Environmental Protection. 2018. China Environmental Economic Accounting Report(2017). B eijing: Environmental Planning Institute of the M inistry of Environmental Protection of China

12. WTO. 2000. Special Study on Trade and the Environment, accessed at: http://www.wto.org/english/tratop_e/envir_e/env ir_e.htm

13. Zhang, J. L., Chang, Y., \& Zhang, L. 2017. Industrial eco-efficiency in China: A provincial quantification using three-stage data envelopment analysis. Journal of cleaner production, 143, 238-249.

14. Zhang, W, Hulin, L., \& Xuebing, A. 2011. Ecological civilization construction is the fundamental way to develop low-carbon economy. Energy Procedia, 5, 839-843. 